\title{
- Autopsy Findings in Covid-19 in a Tertiary Care Teaching Hospital - Case Series
}

\section{IJCRR}

Section: Healthcare

ISI Impact Factor

(2019-20): 1.628

IC Value (2019): 90.81

$\operatorname{SJIF}(2020)=7.893$

(c) (7) (8)

Copyright@IJCRR

\section{Sofiah CS ${ }^{1}$, Swaminathan K', Merla J3, Shantaram K ${ }^{4}$}

'Assistant Professor, Pathology, Tirunelveli Medical College, Tamilnadu, India; ${ }^{2}$ rofessor, Pathology, Tirunelveli Medical College, Tamilnadu, India; ${ }^{3}$ Associate Professor, Pathology, Tirunelveli Medical College, Tamilnadu, India; ${ }^{4}$ Research Coordinator, Department of 1 CMR, Tirunelveli Medical College, Hospital, Tamilnadu, India.

\section{ABSTRACT}

Introduction: Post-mortem studies provide important information for understanding the new disease pathogenesis and clinical outcomes.

Methods: Post-mortem examinations were performed according to WHO guidelines brought dead at tertiary care hospital, Tamilnadu, India. Tissues from the lung, heart, liver, kidney, spleen, and brain were examined.

Results: Lung findings revealed early-stage DAD in 6 out of 10 cases and late-stage DAD in 4 cases, atypical pneumocytes and bronchopneumonia also noted. There is no evidence of myocarditis, hepatitis or encephalitis. Microvascular injury and thrombosis were also detected.

Conclusion: The SARS-CoV-2 infection causes multisystem disease and significant pathological changes seen in most organs in patients with and without comorbidities irrespective of age.

Key Words: Autopsy, COVID-19, SARS-CoV-2, Comorbidities, Pathology

\section{INTRODUCTION}

The pandemic outbreak caused by a new coronavirus infection (severe acute respiratory syndrome coronavirus 2, SARS-CoV-2) disease was reported first in China and spread to many countries worldwide from December 2019. In India, Kerala's state reported the first case of coronavirus infection on 30 January 2020 and had a travel history from Wuhan, China. The new coronavirus, severe acute respiratory syndrome coronavirus-2 (SARS-CoV-2), has infected 37.4 million and caused more than 1.08 million deaths worldwide in India 7.12 million cases and $109 \mathrm{~K}$ death were reported. However, very little is known about the causes of death and the virus's Pathologic features.

The clinical spectrum of SARS-CoV-2 disease (COVID-19) is reported with mild, moderate and severe symptoms. The main symptoms include, a disease with fever, cough, difficulty in breathing, chest pain, vomiting, giddiness, loose stools and $15 \%$ of the symptomatic patients develop pneumonia \& ARDS. ${ }^{1,5}$ SARS-CoV-2 is the seventh member of the coronavirus family identified to cause disease in humans.
Coronaviruses are enveloped, positive-sense, single-stranded RNA viruses. Two other family members, severe acute respiratory syndrome coronavirus (SARS-CoV) and Middle East respiratory syndrome coronavirus (MERS-CoV), cause acute diffuse alveolar damage, pneumocyte hyperplasia, and interstitial pneumonia. ${ }^{2}$

Autopsy plays an important role in understanding and explaining the disease processes and their effects on different organ systems for many centuries. Autopsy helps and enhances the clinical practitioners, about the treatment and management of new diseases such as COVID-19. ${ }^{3,4}$

\section{METHODS}

This is a case series of autopsies conducted in the pathology department at a tertiary care hospital. The hospital recorded ten sudden deaths in community settings and was brought to this teaching hospital's casualty in rural south Tamil Nadu, south India. The post-mortem was carried to find out the cause of death. The chronological evolution of the event

\section{Corresponding Author:}

Shantaram K, 9/1 Happy Colony, Ambai Road, Tirunelveli, Tamilnadu 627005, India.

Email: shantaraman_kal@tvmc.ac.in

ISSN: 2231-2196 (Print) ISSN: 0975-5241 (Online)

Received: $24.04 .2021 \quad$ Revised: 02.07 .2021

Accepted: 16.08 .2021

Published: 20.11 .2021 
leads to the death, time of its occurrence, previous medical history related to the deceased, details of medical therapy, treatment regimen (current and prior) and previous surgical procedures or interventions, and family history of cardiac illness were recorded. Examination of the heart and blood vessels was done as per the standard procedure.

Inclusion criteria: Person dead of sudden cardiac death received in the morgue

Exclusion criteria: No histological changes related to COVID-19

\section{Post-mortem examination}

With the recently published WHO guidelines for suspected COVID-19 cases, Post-mortem examinations were performed in line with it. The autopsy was carried out at the Tirunelveli Medical College, Tamilnadu, India, to establish the cause of death, as all these cases were unexpected deaths of unknown cause.

\section{Diagnostic testing for COVID-19}

To test for COVID-19, swabs were obtained from the trachea, lung parenchyma, pericardium, and pleural cavity. As directed, collected specimens were forwarded to the lab for a real-time reverse transcriptase PCR. ${ }^{7}$

\section{Histology}

Representative samples were obtained from the brain, lung, liver, kidney, spleen and heart submitted in standard tissue cassettes. These were fixed in formalin for 72 hours as per the Centers for Disease Control and Prevention guidance. The virus is rendered inactive by formalin. ${ }^{8}$ Samples were prepared, paraffin-embedded, sectioned, mounted on glass slides, and stained with H\&E, immunohistochemical staining for inflammatory infiltrate and cellular components (including staining with antibodies against CD68, CD3, CD20, CD34) and Special stain Reticulin was performed to demonstrate basement membrane and all slides were examined.

Data were collected using proforma and presented as frequency and percentage.

\section{RESULTS}

Patients were 8 Male and 2 Female, with a mean age of 38.2 years (SD 13; range 16-60)

\section{Table 1: Microscopic Changes} Pathologic Findings of Lungs

Edema

Interstitial Space

Yes No

$5 \quad 5$

Haemorrhage

Congestion

Lymphocytes
Table 1: (Continued)

\begin{tabular}{lccc} 
Pathologic Findings of Lungs & Yes & No \\
& Neutrophils & 6 & 4 \\
& Fibrosis & 4 & 6 \\
Intra Alveolar Space & Edema & 8 & 2 \\
& Cyst Macrophages & 6 & 4 \\
Distorted Alveoli & 9 & 1 \\
Emphysema & 2 & 8 \\
Hyperplasia of Pneumocytes & 7 & 3 \\
Hyaline Membrane Thickening & 4 & 6 \\
Focal Denuded & Epithelia & 1 & 9 \\
Perivascular Lymphocyte & 1 & 9 \\
\hline
\end{tabular}

Table 2: Microscopic Changes

\begin{tabular}{llcc} 
Pathologic Findings of Liver & Yes & No \\
Congested Sinusoids & & 7 & 3 \\
Portal Triad & Haemorrhage & 3 & 7 \\
& Inflammatory Cells & 6 & 4 \\
Fatty Change & & 6 & 4 \\
Congested Vessels & & 4 & 6 \\
\hline
\end{tabular}

Table 3: Microscopic Changes

\begin{tabular}{llcc} 
Pathologic Findings of Kidney & Yes & No \\
Renal Tubules & Distorted/ Atrophied & 10 & o \\
& Haemorrhage & 5 & 5 \\
\multirow{3}{*}{ Glomeruli } & Denuded Epithelium & o & 10 \\
Interstitium & Congestion/Haemorrhage & 10 & 0 \\
& Congestion/Haemorrhage & 9 & 1 \\
& Fibrosis & 7 & 3 \\
\multirow{3}{*}{ Blood Vessels } & Perivascular Lymphocytes & 1 & 9 \\
& Congestion & 6 & 4 \\
& Sclerosis & 1 & 9 \\
\hline
\end{tabular}

\section{Clinical Summary}

The hospital recorded ten sudden deaths in community settings, most of whom had various respiratory symptoms with fever immediately before death. Still, it was not tested for or diagnosed with COVID-19 (Table 1). One case had the significant underlying disease with chronic obstructive pulmonary disease and another case was with type 2 diabetes mellitus.

\section{Microscopic Findings}

Histological examination of lungs given in Table 1 revealed features are corresponding to an early stage of Diffuse Alveolar Damage (DAD) in 6 cases and 4 cases with advanced DAD lesion (Fibroblastic proliferation within interstitial alveolar spaces) and all cases consisted of interstitial 
and intra alveolar oedema (Fig 1) with variable amounts of haemorrhage (Fig 2) and fibrin deposition (Fig 3), hyaline membrane thickening (Fig 4) with minimal interstitial inflammatory infiltrates (Fig 5) mainly composed of CD3 \& CD20lymphocytes located predominantly in the interstitial spaces and around larger bronchioles with focal neutrophils, CD20lymphocytes (Fig 6)seen in aggregates around small vessels and type 2 pneumocyte hyperplasia (Fig 7), CD3 positive T cells (Fig 8), CD68 macrophages (Fig 9), were seen in intra alveolar space, Microthrombi was noted in 4 cases, 2 cases had bronchopneumonia, and one had atypical pneumocytes, and one case had multinucleated giant cells.

Histological examination of liver Table 2showed sinusoidal congestion in 7 cases and extravasation of RBC into the space of Disse. In 6 cases, there was congestion of small veins, steatosis was seen in 7, portal triad lymphocytic infiltration was seen in 6 cases. Spleen, in all cases, showed congestion.

Histological examination of the kidney in Table 3 showed renal tubules, which are distorted/atrophied and haemorrhage noted in all cases. Glomeruli and interstitium showed haemorrhage and congestion and focal fibrosis was also noted in 3 cases.

Histological examination of the brain showed only congestion no evidence of vasculitis, necrosis and perivascular lymphocytes infiltration was noted.

Histological examination of the heart did not show any areas of myocyte necrosis; there was no significant lymphocytic infiltrate consistent with viral myocarditis.

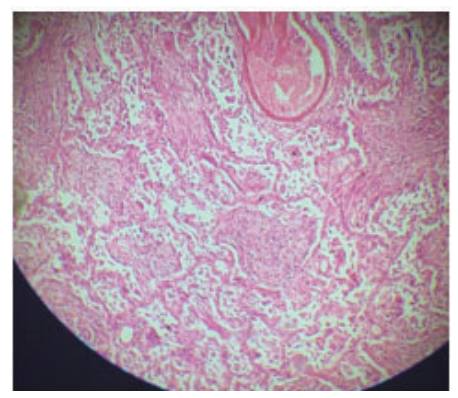

Figure 1: Thickned hyaline membranes.

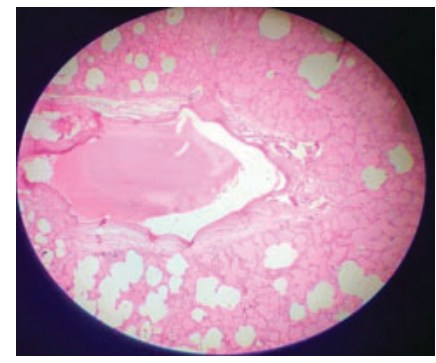

Figure 2: Clumps of fibrin.

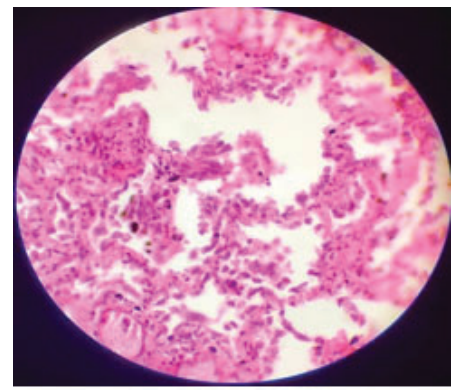

Figure 3: Type 2 pneumocyte hyperplasia with the widening of Alveolar walls.

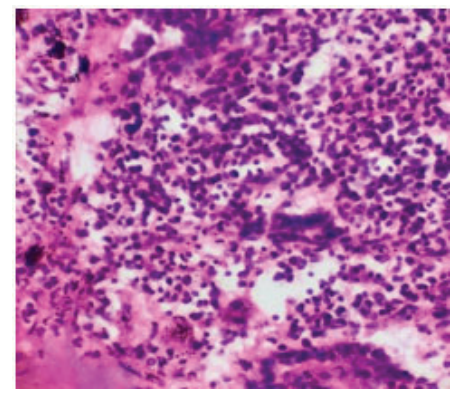

Figure 4: Inflammatory Cells.

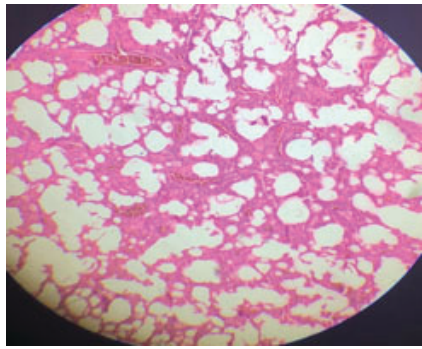

Figure 5: Alveolar haemorrhage.

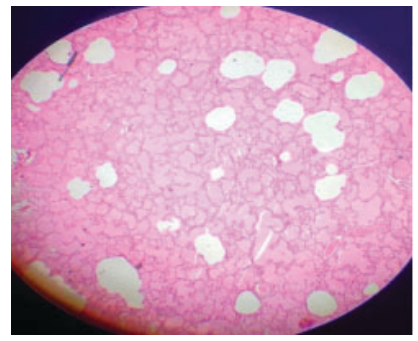

Figure 6: Alveolar Edema.

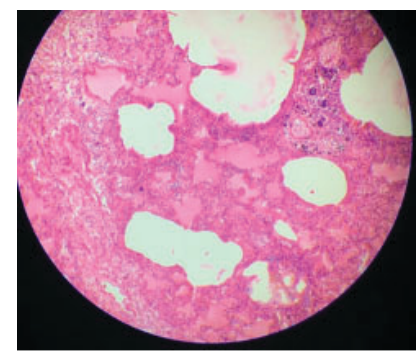

Figure 7: Lung abscess. 


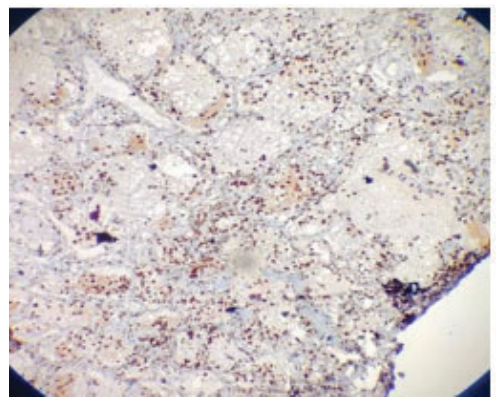

Figure 8a: Immunohistochemistry CD3.

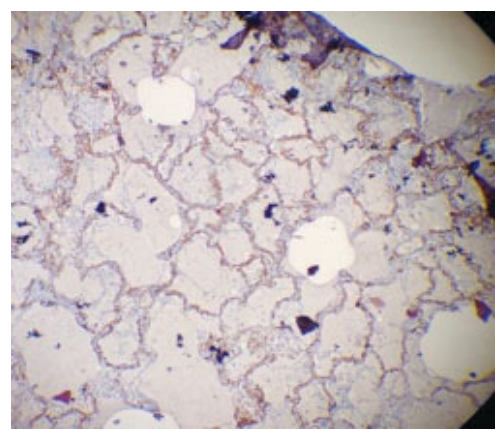

Figure 8b: IHC CD34.

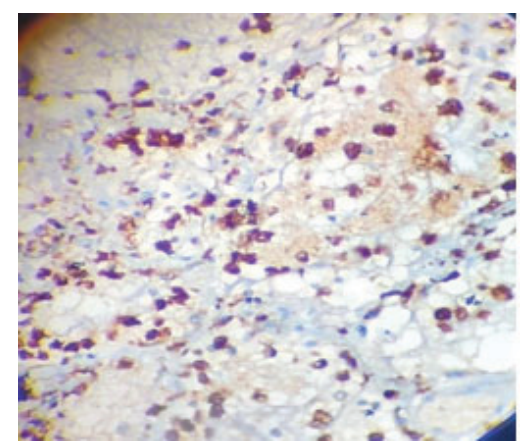

Figure 9: IHC CD 68.

\section{DISCUSSION}

Whole-body autopsies provide various advantages using biopsies and tissues obtained from post mortem ${ }^{5,9,10}$. A fullbody autopsy study was conducted for these cases that were brought dead to establish the cause of death. The case study illustrates the histological changes observed in the COVID-19 infection. Various degrees of lung injury with diffuse alveolar damage associated with multisystem involvement and significant pathology in most body organs where microvascular injury and thrombosis were also seen. Significant histopathological hallmarks of widespread vascular injury are seen in the liver, kidney and spleen. It was also found that type 2 pneumocyte hyperplasia and shedding was prominent in these cases, which were similar to recent studies on SARS-CoV-1 and SARS-CoV-2. ${ }^{11,12,13}$
A case report from China also described findings in a postmortem biopsy specimen, which showed diffuse alveolar damage and interstitial mononuclear inflammatory infiltrates ${ }^{14}$. Our autopsy study found that COVID-19 predominantly causes acute lung injury and diffuse alveolar damage, associated with multisystem involvement and significant pathology across most body organs in patients with and without the comorbid disease. All deaths were due to cardiorespiratory failure, and all cases had extrapulmonary manifestations. Microvascular injury and thrombosis were also detected. The 3 young patients without pre-existing medical conditions also had similar findings despite the absence of comorbidities. They displayed all the histopathological hallmarks of widespread vascular injury, including liver, kidney and spleen $^{15}$.

It is well recognized that older age increases the risk of severe disease or fatality, with $95 \%$ of deaths in those aged over $60 .{ }^{18}$ In this study, all but cases were with (age $<60$ years). However, severe respiratory disease was noted in the three younger adults, reflecting that it is limited to the elderly.

\section{CONCLUSION}

It was noted that viral infection is an important cause of myocarditis. All cases observed various degrees of lung injury with diffuse alveolar damage and widespread vascular injury in the liver, kidney and spleen, which was similar to SARSCoV-1 and SARS-CoV-2.

\section{ACKNOWLEDGEMENT}

Authors acknowledge the immense help received from the scholars whose articles are cited and included in references to this manuscript

\section{Conflict of interest: Nil}

Financial support: No

\section{REFERENCES}

1. Huang C, Wang Y, Li X, Ren L, Zhao J, et al. Clinical features of patients infected with 2019 novel coronavirus in Wuhan, China. The lancet. 2020 Feb 15;395(10223):497-506.

2. Carsana L, Sonzogni A, Nasr A, Rossi RS, Pellegrinelli A, et al. Pulmonary post-mortem findings in a series of COVID-19 cases from northern Italy: a two-centre descriptive study. Lancet Infect Dis. 2020 Oct 1;20(10):1135-1140.

3. Youd E, Moore L. COVID-19 autopsy in people who died in community settings: the first series. J Clin Pathol. 2020 Dec 1;73(12):840-844.

4. Schaller T, Hirschbühl K, Burkhardt K, Braun G, Trepel M, et al. Postmortem examination of patients with COVID-19. Jama. 2020 Jun 23;323(24):2518-2520. 
5. Xu Z, Shi L, Wang Y, Zhang J, Huang L, et al. Pathological findings of COVID-19 associated with acute respiratory distress syndrome. Lancet Respir Med. 2020 Apr 1;8(4):420-422.

6. Fox SE, Akmatbekov A, Harbert JL, Li G, Brown JQ, Vander Heide RS. Pulmonary and cardiac pathology in African American patients with COVID-19: an autopsy series from New Orleans. Lancet Respir Med. 2020 Jul 1;8(7):681-6.

7. Wang D, Hu B, Hu C, Zhu F, Liu X, et al. Clinical characteristics of 138 hospitalized patients with 2019 novel coronavirusinfected pneumonia in Wuhan, China. J Am Med Ass. 2020 Mar 17;323(11):1061-1069.

8. Healthcare Workers [Internet]. Centres for Disease Control and Prevention. 2020 [cited 10 April 2020]. Available from: https:// www.cdc.gov/coronavirus/2019-ncov/hcp/guidance-postmortem-specimens.html

9. Tian S, Xiong Y, Liu H, Niu L, Guo J, et al. Pathological study of the 2019 novel coronavirus disease (COVID-19) through postmortem core biopsies. Mod Pathol. 2020 Jun;33(6):1007-1014.

10. Konopka KE, Wilson A, Myers JL. Postmortem lung findings in a patient with asthma and coronavirus disease 2019. Chest. 2020 Sep 1;158(3):e99-101.

11. Su H, Yang M, Wan C, Yi LX, Tang F, et al. Renal histopathological analysis of 26 post-mortem findings of patients with COVID-19 in China. Kidney Int. 2020 Jul 1;98(1):219-227.

12. Xu Z, Shi L, Wang Y, Zhang J, Huang L, et al. Pathological findings of COVID-19 associated with acute respiratory distress syndrome. Lancet Respir Med. 2020 Apr 1;8(4):420-2.
13. Franks TJ, Chong PY, Chui P, Galvin JR, Lourens RM, et al. Lung pathology of severe acute respiratory syndrome (SARS): a study of 8 autopsy cases from Singapore. Hum Pathol. 2003 Aug 1;34(8):743-748.

14. Tian S, Xiong Y, Liu H, Niu L, Guo J, et al. Pathological study of the 2019 novel coronavirus disease (COVID-19) through postmortem core biopsies. Mod Pathol. 2020 Jun;33(6):1007-1014.

15. Falasca L, Nardacci R, Colombo D, Lalle E, Di Caro A, et al. Postmortem findings in Italian patients with COVID-19: a descriptive full autopsy study of cases with and without comorbidities. J Infect Dis. 2020 Dec 1;222(11):1807-1815.

16. Barton LM, Duval EJ, Stromberg E, Ghosh S, Mukhopadhyay S. Covid-19 autopsies, Oklahoma, USA. Am J Clin Pathol. 2020 May 5;153(6):725-733.

17. Lupia T, Scabini S, Pinna SM, Di Perri G, De Rosa FG, et al. 2019 novel coronavirus (2019-nCoV) outbreak: A new challenge. J Glob Antimicrob Resist. 2020 Jun 1;21:22-27.

18. Statement - Older people are at the highest risk from COVID-19, but all must act to prevent community spread [Internet]. Euro.who.int. 2020 [cited 19 April 2020]. Available from: https://www.euro.who.int/en/health-topics/health-emergencies/ coronavirus-covid-19/statements/statement-older-people-are-athighest-risk-from-covid-19,-but-all-must-act-to-prevent-community-spread 